\title{
Circadian influences on myocardial infarction
}

\section{Jitka A. I. Virag * and Robert M. Lust}

Department of Physiology, Brody School of Medicine, East Carolina University, Greenville, NC, USA

\section{Edited by:}

Ovidiu Constantin Baltatu, University Camilo Castelo Branco, Brazil

\section{Reviewed by:}

Urs Albrecht, University of Fribourg,

Switzerland

Jacqueline Kathleen Phillips,

Macquarie University, Australia

Luciana A. Campos, University

Camilo Castelo Branco, Brazil

*Correspondence:

Jitka A. I. Virag, Department of

Physiology, Brody School of

Medicine, East Carolina University,

600 Moye Blvd., 6N-98, Greenville,

NC 27834, USA

e-mail: viragj@ecu.edu
Components of circadian rhythm maintenance, or "clock genes," are endogenous entrainable oscillations of about $24 \mathrm{~h}$ that regulate biological processes and are found in the suprachaismatic nucleus (SCN) and many peripheral tissues, including the heart. They are influenced by external cues, or Zeitgebers, such as light and heat, and can influence such diverse phenomena as cytokine expression immune cells, metabolic activity of cardiac myocytes, and vasodilator regulation by vascular endothelial cells. While it is known that the central master clock in the SCN synchronizes peripheral physiologic rhythms, the mechanisms by which the information is transmitted are complex and may include hormonal, metabolic, and neuronal inputs. Whether circadian patterns are causally related to the observed periodicity of events, or whether they are simply epi-phenomena is not well established, but a few studies suggest that the circadian effects likely are real in their impact on myocardial infarct incidence. Cycle disturbances may be harbingers of predisposition and subsequent response to acute and chronic cardiac injury, and identifying the complex interactions of circadian rhythms and myocardial infarction may provide insights into possible preventative and therapeutic strategies for susceptible populations.

Keywords: myocardial infarction, circadian rhythm, acute ischemia, remodeling, cardioprotection

\section{CLINICAL ASSOCIATIONS FOR CIRCADIAN RHYTHMS IN MYOCARDIAL INFARCTION}

The ability to properly synchronize with the external environment is an essential element of animal survival. The predation rate of free-living chipmunks increased over time in suprachiasmatic nucleus (SCN)-lesioned animals due to their reduced burrowing during the nighttime (Decoursey et al., 2000). On the other hand, rats kept in total darkness during the first $48 \mathrm{~h}$ following brain injury exhibited improved recovery (Corwin and Vargo, 1993; Vargo et al., 1998, 1999). In humans, disruptions in rhythms are associated with reduced survival of patients with metastatic cancers (Mormont et al., 2000; Sephton et al., 2000) and alterations in expression of clock genes have been shown to be responsible for unregulated cell growth (Granda et al., 2005; Chu et al., 2008; Clairambault, 2008; Yang et al., 2008).

The significance of circadian rhythms to myocardial infarction has been identified in several studies in which onset of non-Qwave angina, unstable angina, myocardial infarctions, and sudden cardiac death all show marked elevations in occurrence between the hours of 0600 and 1200 (Muller, 1999a,b; Willich et al., 2004; Mosendane and Raal, 2008). Ethnic genetic, medications, comorbidities, lifestyle, cultural, and/or social factors may shift the time of highest incidence (Kanth et al., 2013). Lopez et al. (2005) and Savopoulos et al. (2006) each reported a significant shift to the 1800-2400 $\mathrm{h}$ window for increased incidence of sudden death in Mediterranean populations. The incidence of ischemic stroke, has been reported to follow the same patterns (Gupta and Shetty, 2005), with highest incidence in the 0600-1200 window and diurnal variation in ventricular arrhythmias have recently been demonstrated to be related to abnormal repolarization (Jeyaraj et al., 2012). The time of day when an event occurs also may influence the severity of the outcome (Mukamal et al., 2000) and also may extend to the timing of salvaging intervention. The time of day when mechanical reperfusion by percutaneous transluminal coronary angioplasty (PTCA) is performed influences subsequent 1 year mortality rates, with patients treated between 0400 and 0800 having worse outcomes than all others, even after correcting for confounding variables (De Luca et al., 2005).

Blood pressure normally follows a diurnal pattern, with pressures lowest at night, and rising to a peak in the hours 0600-1000. Several ambulatory blood pressure studies have identified that failure to decrease blood pressure at night, so called "non-dipping," is associated with increased cardiovascular risk (Morgan, 2002; Lee et al., 2005; Izzedine et al., 2006), and optimal efficacy in relation to time of day is a major factor considered in anti-hypertensive drug development (Lemmer, 2006). More recently, it has been shown that Per2 mutation diminishes blood pressure and heart rate dipping (Vukolic et al., 2010). Many intrinsic vasoactive and cardioactive substances, such as angiotensin II, melatonin, plasminogen activator inhibitor 1 (pai1), glucocorticoids, epinephrine, norepinephrine, and nitric oxide follow distinct circadian patterns (Ding et al., 1994; Balsalobre et al., 2000; McNamara et al., 2001; Nonaka et al., 2001; Naito et al., 2003; Tsuchiya et al., 2005; Tsujino et al., 2005; Vaughan, 2005; Kanth et al., 2013). To the extent that diabetes and obesity are contributing factors to cardiovascular risk, recent reviews associating circadian genes with metabolic dysfunction in peripheral tissues are noteworthy. And whether these many circadian patterns are causally related to the observed periodicity of events, or whether they are simply epiphenomena is not well established, 
but a few studies suggest that the circadian effects likely are real in their impact on myocardial infarction incidence (Bray and Young, 2007; Green et al., 2008; Prasai et al., 2008; Ruger and Scheer, 2009; Durgan and Young, 2010; Maury et al., 2010; Bailey et al., 2014; Nedeltcheva and Scheer, 2014). Chronic instability in circadian rhythm in shift worker studies was recognized more than 20 years ago to produce increased risk of cardiovascular morbidity and mortality (Knutsson et al., 1986). More recently, Fujino et al. (2006) reported that the relative risk for ischemic heart disease in Japanese factory workers on rotating shifts doubles compared to that of workers with either fixed daytime or fixed night-time schedules. Kawachi et al. reported similar findings in a study of U.S. nurses, with the multivariate risk increasing commensurate with the duration of rotating shift work (Kawachi et al., 1995). Notably, in hamsters with a mutation producing a $22 \mathrm{~h}$ circadian cycle, premature cardiac mortality was noted, and corrected when either the animals were converted to a $22 \mathrm{~h} \mathrm{~L} / \mathrm{D}$ cycle matching the phenotype, or the SCN was ablated, abolishing the dys-synchrony (Martino et al., 2008). Further, the same group also demonstrated that when mice were maintained in a disrupted light/dark (L/D) rhythm (10/10 vs. normal 12/12), the hypertrophy response to aortic banding was badly impaired (Martino et al., 2007).

These findings are consistent with the premise that synchronization between the central and peripheral clocks is a continuous, ongoing process, and that the pressure to maintain this synchronization involves signaling mechanisms that are energetically demanding for the peripheral target tissues. When coupled with an underlying pathophysiology that generates a vulnerable substrate, such as coronary artery disease or pressure overload, the pressure to normalize desynchronized rhythms increases the progression of injury.

\section{CIRCADIAN RHYTHM BIOLOGY}

Circadian rhythms are daily variations of physiological functions that are found in every living organism. These daily rhythms are generated through the integration of oscillatory expression of multiple circadian clock genes (Harmer et al., 2001; Dvornyk et al., 2003; Merrow et al., 2005; Granados-Fuentes and Herzog, 2013). In mammals, the circadian rhythms are regulated by the SCN of the hypothalamus. Neurons in the SCN generate selfsustained daily oscillations of gene expression and electrical activity with a frequency of close to $24 \mathrm{~h}$ (Herzog and Schwartz, 2002). The SCN keeps the circadian rhythms of different peripheral organs synchronized to each other as well as to the environmental light-dark cycle (Dardente and Cermakian, 2005). Although every mammalian cell is believed to express the circadian clock genes, it has been shown that some cells outside the SCN are not able to maintain self-sustained circadian oscillation in the absence of the SCN (Fukuhara and Tosini, 2003).

Major progress has been made in identifying genes that regulate the circadian clock (Hardin and Glossop, 1999; Reppert and Weaver, 2002; Hardin, 2006; Hardin and Panda, 2013). The first circadian clock gene was identified in drosophila, named Period (per) (Kyriacou and Hall, 1980). The first mammalian counterpart of the Period gene was discovered by Sun et al. (1997). Molecular components of the circadian clock have been identified in mammals and interact to contribute to the entrainment and pace making of the circadian rhythm. These genes include a clock gene, a gene encoding brain-muscle Arnt-like protein 1 (bmal1) (Honma et al., 1998), three period genes (per1, per2, and per3) (Sun et al., 1997; Zheng et al., 1999; Shearman et al., 2000), and two cryptochrome genes (cry1 and cry2) (Thresher et al., 1998; Hardin and Glossop, 1999; Sancar, 2000). In addition, there is evidence that the NPAS2 gene, which encodes a functional analog of the clock, may play a role in the functioning of the circadian clock in the brain as well as peripheral organs (Reick et al., 2001; Hardin, 2006).

These clock genes participate in the pacemaking and phase regulation of the circadian rhythm. In the mammalian cells, CLOCK/BMAL1 form heterodimers that are positive regulators which activate the transcription of per1, per2, and per3 through a transcription factor binding site, located in the promoter region of the per genes. Per1, per2, and per3 mRNA are transcribed and move to the cytoplasm, where they are translated into PER1, PER2, and PER3 proteins. As the levels of PER1 and PER2 proteins increase and begin to form PER1/PER2 heterodimers, the protein complex enters the nuclei. However, nuclear translocation of the PER1/PER2 heterodimers is tightly regulated. Cryptochrome proteins, CRY1 and CRY2, negatively regulate clock feedback while PER3 enhances translocation of PER1 and PER2 to the nucleus (Sangoram et al., 1998; Glossop et al., 1999; Kume et al., 1999; Shearman et al., 2000; Yagita et al., 2000; Lee et al., 2001). Doubletime (or casein kinase Ie in mouse), can bind and phosphorylate PER1 and PER2, thereby masking PER1's nucleus localization signaling, promoting its retention in the cytoplasm and thereby its degradation (Glossop et al., 1999; Xu et al., 2007). In addition, CRY1/CRY2 act as lightindependent inhibitors of CLOCK/BMAL1, thereby suppressing the per genes transcriptions (Sancar, 2000). This auto-regulatory feedback mechanism of clock gene expression serves as the basis for the temporal oscillation of the circadian clock (Hardin, 2006; Xu et al., 2007). REV-ERBA forms an accessory loop which periodically represses transcription of BMAL1, serving to stabilize the oscillator (Guillaumond et al., 2005; Reddy and Maywood, 2007). Although every mammalian cell is believed to express the circadian clock genes, it was held that cells outside the SCN could not maintain self-sustained circadian oscillation in the absence of the SCN (Fukuhara and Tosini, 2003). However, parabiosis studies and isolated cell culture studies clearly indicate that individual tissues can produce sustained intrinsic circadian rhythms independent of the SCN (Nagoshi et al., 2004, 2005; Davidson et al., 2005; Durgan et al., 2005; Guo et al., 2005). However, signals from the SCN or an environmental trigger are required to keep the individual cell rhythms in synchrony with each other. The mechanism of communication between the SCN and the bone marrow which produces regenerative cell populations that may assist in wound healing, the physiologic implications, and means to exploit circadian rhythms for clinical purposes are currently being investigated (Bourin et al., 2002; Tsinkalovsky et al., 2005, 2007; Scadden, 2008). There have been shown to be diurnal variations in granulocyte-colony stimulating factor (G-CSF) that alter the levels of circulating stem cells (Jilma et al., 1999). MendezFerrer et al. (2008) showed that the circadian clock regulates 
bone marrow-derived SDF- $1 \alpha$ via neuronal $\beta_{3}$-adrenergic receptors.

It is clear that there is increased understanding of the basic nature by which a rhythmic gene expression can be produced. It is also clear that, other than output from a central clock, the manner by which a given peripheral clock is synchronized with another, or the extent to which a peripheral clock can establish feedback to the SCN that it is, in fact, synchronized is not known. At present, the literature does support the premise that pathophysiologic conditions can both cause uncoupling of peripheral oscillators and be caused by uncoupling of peripheral clocks (Muller, 1999a,b; Young et al., 2001a,b; Willich et al., 2004; Lee et al., 2005; Fujino et al., 2006; Maywood et al., 2010; Tsimakouridze et al., 2012; Reddy and Rey, 2014; Robinson and Reddy, 2014; Wu and Reddy, 2014).

\section{CIRCADIAN EFFECTS AND ACUTE ISCHEMIA/REPERFUSION INJURY}

Ischemia/reperfusion (I/R) injury occurs when an artery that supplies the ventricular tissue becomes obstructed and limits blood flow, and thus oxygen and nutrients as well as waste removal. If this occlusion persists, the damage becomes irreversible. If flow can be reinstated (reperfusion), tissue can be salvaged but there is ancillary oxidative stress (Anaya-Prado et al., 2002; Kaminski et al., 2002; Hamacher-Brady et al., 2006). I/R injury is a complex process involving vascular and endothelial dysfunction, metabolic and mitochondrial dysfunction, necrosis, apoptosis, and functional deficits, even in tissue without permanent cellular injury (Jordan et al., 1999; Giordano, 2005; Seal and Gewertz, 2005; Cohen et al., 2006). A common feature of $I / R$ injury is an inflammatory reaction, with infiltration of polymorphonuclear leukocytes (PMN), predominantly neutrophils which have been causally linked to myocardial damage during reperfusion injury (Jordan et al., 1999). Release of elastases, lipases, and proteases and peroxidases from azurophilic granules of neutrophils as well as reactive oxygen species (ROS) generated by NADPH oxidase in neutrophil membranes can result in direct myocyte damage (Rossi, 1986; Frangogiannis et al., 1996; Takayama et al., 2004). The interaction between neutrophils and endothelial cells is mediated by interactions at the vascular interface of different cell adhesion molecules including selectins, $\beta_{2}$-integrins, and the immunoglobulin superfamily (Jones et al., 1999). Hypoxia and cytokines released from ischemic myocardium result in upregulation of these adhesion markers on endothelial surfaces as well as on the surface of neutrophils, thereby facilitating neutrophil recruitment to the tissue during reperfusion (Frangogiannis et al., 1996).

Inflammation plays a key role in the development and progression of myocardial infarction and neutrophil infiltration is a defining feature of ischemic cardiac diseases (Jordan et al., 1999). Reperfusion injury following revascularization procedures is a major cause of myocardial tissue damage, and, accordingly, reperfusion elevates proinflammatory cytokines and infiltration of neutrophils into the tissue (Welbourn et al., 1991; Frangogiannis et al., 1996).IL-1 $\beta$ and TNF- $\alpha$ have direct effects on cardiomyocytes (Suzuki et al., 2001; Chandrasekar et al., 2003), and TNF- $\alpha$ and IL- 6 prime inflammatory cells, increasing their response to soluble proinflammatory mediators such as $N$-formyl peptides, C5a, and platelet-activating factors (Jordan et al., 1999). Infiltrated neutrophils cause tissue destruction by release of elastases, proteases, and superoxide radicals (Rossi, 1986; Rotrosen, 1992; Jordan et al., 1999). Many facets of immune function demonstrate diurnal patterns (Curtis et al., 2014).

Oxidant stress is a finely modulated event in normal physiology. The most common sources of routine oxidant burdens result from normal metabolic activity and mitochondrial electron transfer to molecular oxygen in the mitochondria at complexes I and III of the electron transport chain, producing superoxide and other ROS. Normally, excess ROS is scavenged and neutralized by the actions of enzymes like superoxide dismutase (SOD) and glutathione peroxidase (Taniyama and Griendling, 2003). Melatonin, a hormone with well-established circadian characteristics, has been reported to be a strong regulator of nitric oxide synthase (NOS) (Aydogan et al., 2006). Attenuated increases in night-time melatonin levels in hospitalized patients following angioplasty were correlated positively with increases in C-reactive peptide (CRP), an acute phase inflammatory marker, and were predictive of increased risk of event in the next 6 months (Dominguez-Rodriguez et al., 2006a,b). These findings, suggesting that melatonin is cardioprotective, and are consistent with reports that melatonin is an anti-oxidant, and stimulates antioxidant gene production (Hardeland et al., 2003). In isolated rat hearts, melatonin reduced necrosis and infarct size by inhibiting the mitochondrial permeability transition pore (MPTP) opening which reduced NAD+ and cytochrome c release (Petrosillo et al., 2009). However, Genade et al. reported that the addition of melatonin to isolated, perfused rat hearts abolished the cardioprotective effects induced by ischemic pre-conditioning (IPC) (Genade et al., 2006). The effect was attributed to melatonin's free radical scavenging ability, diminishing the level of ROS below those necessary to trigger the cardioprotective response. Nitric oxide, when produced in normal amounts, is an important signaling molecule, but when present in excess amounts may contribute to protein nitrosylation and ROS generation. In vascular disease, uncoupled activity of NOS, or production of ROS in excess of endogenous antioxidant capacity, leads to oxidative stress which turns into an abnormal vascular response (Cohen, 1995; Taniyama and Griendling, 2003; Lyle and Griendling, 2006). In $\mathrm{I} / \mathrm{R}$, a cascade of events occurs that prevents proper NOSprotein interactions, altering NOS function and NADPH oxidase activity, thereby altering myocyte function. However, two recent reviews highlight the fact that there remains significant disagreement regarding whether and how NO and isoforms of NOS contribute to, or inhibit cardioprotection, particularly in the setting of IPC (Cohen et al., 2006; Jones and Bolli, 2006). Lapenna et al. reported that glutathione peroxidase activity displayed circadian rhythm in the heart, which corresponded with sensitivity to $\mathrm{H}_{2} \mathrm{O}_{2}$-induced oxidative myocardial damage (Lapenna et al., 1992).

Circadian control of homeostatic functions is controlled by environmental and endogenous influences. Circadian genes have the capacity to regulate systems that modulate oxidant burdens, and therefore may potentially contribute significantly to the outcome of I/R or IPC-induced cardioprotection. 
A central element of ischemia is hypoxia. The principal oxygen sensing molecule within the myocardium is hypoxia inducible factor 1 alpha $(H I F-1 \alpha) . H I F-1 \alpha$ is a basic helix-loop-helix PAS domain transcription factor. It is present as a cytosolic protein that is constitutively degraded, but under hypoxic conditions is phosphorylated, which stabilizes it, enabling nuclear translocation. In the nucleus $H I F-1 \alpha$ forms heterodimers with the aryl hydrocarbon nuclear translocase (ARNT), or HIF-1 $\beta$, and binds to hypoxia response elements in the promoter region of a wide range of genes, including those regulating angiogenesis vascular endothelial growth factor (VEGF), metabolism (especially genes coding for glycolytic enzymes), apoptosis, and vasomotor reactivity (NOS) (Semenza, 2001; Yamakawa et al., 2003; Giordano, 2005). Of particular note is that there is thought to be considerable homology in the binding characteristics of Per2 and $H I F-1 \alpha$, such that cross talk has been reported between the circadian gene CLOCK, and HIF-1 $\alpha$ in the regulation of vasopressin gene (Ghorbel et al., 2003). In addition, Koyonagi et al. reported that Per2 expression attenuated hypoxic induction of VEGF expression in a dose dependent manner (Koyanagi et al., 2003). The presumed mechanism was that Per2 bound to $H I F-1 \alpha$, thus blocking nuclear translocation and preventing $H I F-1 \alpha$ induced transcription of VEGF. Constitutively stable hybrids of $H I F-1 \alpha$ were cardioprotective in cultured rat cardiomyocyctes exposed to simulated I/R injury (Date et al., 2005) and led to increases in several genes also induced by IPC, including HSP-70. However, HIF-1 $\alpha$ also is known to be overexpressed in heart failure, which could represent a failure of a sustained attempt to compensate, or it could be that long-term expression is maladaptive. The literature does not yet provide a clear indication which is more likely (Giordano, 2005).

Perhaps the most potent cardioprotection is mediated by signaling cascades activated by IPC, and more recently as described in association with ischemic post-conditioning as well. As reperfusion injury is multi-faceted, it appears that biologic preconditioning is capable of inducing protective responses that also are multi-faceted. Among many mechanisms associated with IPC, activation of the AKT, MAPK, Mek-Erk1/2 pathways, PKC $\varepsilon$, HSP 70 , mitochondrial $\mathrm{K}_{\mathrm{ATP}}$ channels, GSK-3 $\beta$, and HIF- $1 \alpha$ regulated genes all have been implicated (Murphy, 2004; Hausenloy et al., 2005; Crisostomo et al., 2006; Zhao and Vinten-Johansen, 2006; Das et al., 2008; Wong et al., 2010). The mitochondria, the source of ATP for the cardiomyocyte, also generate ROS when the tissue is damaged and so much research is aimed at improving mitochondrial energy production and reduce apoptosis to reduce infarct size (Di Lisa et al., 1998; Oldenburg et al., 2002; Krieg et al., 2003; Marin-Garcia and Goldenthal, 2004; Costa et al., 2005; Murphy and Steenbergen, 2007). Inhibiting the phosphorylation of glycogen synthase beta (GSK-3 $\beta$ ) has been shown to reduce $I / R$ injury but the mechanism have not yet been fully elucidated (Tong et al., 2002; Gross et al., 2004, 2006, 2007; Murphy and Steenbergen, 2005; Mozaffari and Schaffer, 2008; Omar et al., 2010). Possibilities include modulation of mitochondrial function via the MPTP and the voltage-dependent anion channel (VDAC) but further investigation to illuminate the pathway is needed (Mattson and Kroemer, 2003; Marin-Garcia and
Goldenthal, 2004; Di Lisa et al., 2007; Schwertz et al., 2007; Costa and Garlid, 2008; Das et al., 2008; Garlid et al., 2009).

The presumed benefit of independent peripheral oscillators is the ability to anticipate, at the cellular level, changes driven by the SCN in response to environmental cues. Cardiac tissue expresses all known isoforms of cry and per genes, with cry2, per1, and per2 expressed to the greatest degree (Young, 2006). Elements of functioning circadian oscillators are present in cardiac tissue cells:

- Vascular endothelium and smooth muscle show significant circadian variability in functional response (Nonaka et al., 2001; Kawano and Ogawa, 2005; Tsujino et al., 2005; Walters et al., 2006; Viswambharan et al., 2007; Yagita et al., 2010) and dysfunction of these cells types are characteristics of I/R injury (Hazarika et al., 2004; Cozzi et al., 2006).

- Fibroblasts, cells intimately involved in remodeling postinfarction myocardium (Chintalgattu and Katwa, 2004; Squires et al., 2005), show robust circadian responses in culture (Chintalgattu and Katwa, 2004; Nagoshi et al., 2004, 2005; Squires et al., 2005).

- Per2 also has been shown recently to modulate cytokine release in some inflammatory cells (Liu et al., 2006), and inflammation responses are common feature of I/R injury (Welbourn et al., 1991; Jordan et al., 1999; Albert, 2000; Frangogiannis et al., 2002; Albert et al., 2003; Hazarika et al., 2004; Cozzi et al., 2006; Liu et al., 2006).

- Circadian genes appear to regulate a panel of genes encoding for cardiac metabolic enzymes, and it has been postulated that a major role for circadian genes in heart is to synchronize cardiomyocyte metabolic activity (fatty acid vs. glycolytic preferences) with dietary meal induced oscillations in plasma substrate availability. The ability to shift substrates from fatty acid to glycolytic sources is an important characteristic determining functional recovery from I/R injury (Stanley, 2004; Sambandam et al., 2006).

Recent studies examining the role of mPer2 in vivo are conflicting. We have shown that mPer2-mutant mice had less severe injury in acute I/R and chronically non-reperfused MI (Virag et al., 2010, 2013). Conversely, Eckle's group has shown that Per2 is cardioprotective and this tolerance may be by virtue of adenosine-elicited stabilization of Per2, modulation of metabolism, and/or inflammation (Eckle et al., 2012; Bonney et al., 2013a,b; Eltzschig et al., 2013). Lipkova et al. showed that Per3 VNTR polymorphism in humans influences the onset of pain associated with acute MI (Lipkova et al., 2014). Alibhai et al. recently demonstrated that post-MI remodeling is worsened by circadian rhythm disruption (Alibhai et al., 2014).

There is clearly a strong confluence between cascades participating in I/R injury and those regulated by circadian genes. Specific and comprehensive studies examining the effects of each circadian gene and/or circadian rhythm variations on myocardial I/R injury, its modulation by IPC, and how these acute responses might influence the subsequent post-infarction remodeling are only recently beginning to be addressed. 


\section{CHRONIC MYOCARDIAL INFARCT REPAIR AND CIRCADIAN RHYTHM GENES}

Myocardial infarction is an inflammatory disease. Irreversible ischemic injury begins within $20 \mathrm{~min}$ of severe ischemia in vivo and is complete within an hour (Holmes et al., 2005). Myocyte, fibroblast, vascular smooth muscle, and endothelial cell death progresses as a wavefront from subendocardial to subepicardial wall (Reimer and Jennings, 1979). Within $24 \mathrm{~h}$, neutrophils infiltrate from the periphery and macrophages follow within $48 \mathrm{~h}$. Neutrophils gradually apoptose by 5 days but macrophages persist in the infarct throughout repair. The breakdown of intercellular collagen fibrils begins by post-translational activation of matrixmetalloproteinases (MMPs). The increased ratio of MMPs relative to tissue inhibitors of matrixmetalloproteinases (TIMPs) propagates this degradation that begins within hours and proceeds for 3-4 days (Vanhoutte et al., 2006). As the matrix disintegrates, myocyte slippage occurs (Cleutjens et al., 1995). Myocyte necrosis, evidenced by contraction bands and pyknosis, as well as dead vascular elements are completely phagocytosed by macrophages within 2 weeks (Baroldi, 1988; Virag and Murry, 2003; Holmes et al., 2005). Between 4 and 7 days granulation tissue, comprised of proliferating fibroblasts and endothelial cells, forms by migration of these cells from the border zone into the infarct core (Virag and Murry, 2003). During this process, a variety of factors are evolved from macrophages, including chemokines such as MCP-1, cytokines such as IL-1 and G-CSF, and ROS such as nitric oxide and superoxide anion (Byrne et al., 2003; Kumar and Jugdutt, 2003; Nian et al., 2004; Frangogiannis and Entman, 2005; Frangogiannis, 2006; Maulik, 2006). These molecules can also cause considerable damage to surrounding viable cells and result in further spreading of the infarct. By 2 weeks, the young scar is characterized by the parallel organization of fibroblasts and predominance of Type I fibrillar collagen (Sun et al., 2002; Virag and Murry, 2003). As the matrix becomes increasingly more fibrotic, endothelial cells, fibroblasts and macrophages begin to apoptose, resulting in vascular regression (Frangogiannis et al., 2002; Virag and Murry, 2003). Further, perivascular fibrosis and disarrayed hypertrophy will not be balanced by the coronary blood flow reserve and the consequent hypoperfusion may cause myocardial ischemia. Progressive thinning and stretching of the non-contractile scar tissue continues, resulting in increased chamber dimensions and increased wall stress. Subsequent volume-overload hypertrophy of the surviving myocardium ensues, but this is insufficient to maintain pressure development. Ultimately, this leads to inadequate pumping and overt heart failure (Pfeffer and Braunwald, 1990; Opie et al., 2006). Cardiac hypertrophy and failure also entail dysfunction of mitochondrial energy and substrate metabolism. Impaired mitochondrial function is associated with a decline in high-energy phosphates, reduced oxygen consumption, and decreased expression and activity of complexes I through IV of the respiratory chain. Therefore, the signaling cascades described above that are active during preconditioning should also be investigated as remodeling progresses. Since circadian clocks in peripheral tissues can disturb and be disturbed by genetic and/or lifestyle- related pathologies, modulation of these mediators may be potentially exploited as novel chronotherapeutic targets for treatment and prevention of these conditions.

\section{CONCLUSION}

A complex sequence of various cellular activities orchestrate myocardial infarct injury and healing. The importance of circadian genes and/or rhythms is also evident, however, the precise mechanisms are only beginning to be addressed. In depth analyses of macrophage, endothelial cell, and fibroblast behavior in vivo in both the acute and chronic phases of infarct repair in genetically modified mice (tissue-specific and global) as well as carefully constructed approaches to sort out cause and effect with respect to circadian genes, rhythm variations, and injury will illuminate signaling cascades that may potentially be exploited to yield more efficacious myocardial infarct healing. This information can then be applied to mitigate myocardial infarction in the presence of pathologies and other confounding variables that may be involved in governing disease severity and progression.

\section{REFERENCES}

Albert, M. A. (2000). The role of C-reactive protein in cardiovascular disease risk. Curr. Cardiol. Rep. 2, 274-279. doi: 10.1007/s11886-000-0081-7

Albert, M. A., Glynn, R. J., and Ridker, P. M. (2003). Plasma concentration of Creactive protein and the calculated Framingham Coronary Heart Disease Risk Score. Circulation 108, 161-165. doi: 10.1161/01.CIR.0000080289.72166.CF

Alibhai, F. J., Tsimakouridze, E. V., Chinnappareddy, N., Wright, D. C., Billia, F., O'Sullivan, M. L., et al. (2014). Short-term disruption of diurnal rhythms after murine myocardial infarction adversely affects longterm myocardial structure and function. Circ. Res. 114, 1713-1722. doi: 10.1161/CIRCRESAHA.114.302995

Anaya-Prado, R., Toledo-Pereyra, L. H., Lentsch, A. B., and Ward, P. A. (2002). Ischemia/reperfusion injury. J. Surg. Res. 105, 248-258. doi: 10.1006/jsre.2002.6385

Aydogan, S., Yerer, M. B., and Goktas, A. (2006). Melatonin and nitric oxide. J. Endocrinol. Invest. 29, 281-287. doi: 10.1007/BF03345555

Bailey, S. M., Udoh, U. S., and Young, M. E. (2014). Circadian regulation of metabolism. J. Endocrinol. 222, R75-R96. doi: 10.1530/JOE-14-0200

Balsalobre, A., Brown, S. A., Marcacci, L., Tronche, F., Kellendonk, C., Reichardt, H. M., et al. (2000). Resetting of circadian time in peripheral tissues by glucocorticoid signaling. Science 289, 2344-2347. doi: 10.1126/science.289.54 88.2344

Baroldi, G. (1988). Anatomy and quantification of myocardial cell death. Methods Achiev. Exp. Pathol. 13, 87-113.

Bonney, S., Hughes, K., Harter, P. N., Mittelbronn, M., Walker, L., and Eckle, T. (2013a). Cardiac period 2 in myocardial ischemia: clinical implications of a light dependent protein. Int. J. Biochem. Cell Biol. 45, 667-671. doi: 10.1016/j.biocel.2012.12.022

Bonney, S., Kominsky, D., Brodsky, K., Eltzschig, H., Walker, L., and Eckle, T. (2013b). Cardiac Per2 functions as novel link between fatty acid metabolism and myocardial inflammation during ischemia and reperfusion injury of the heart. PLoS ONE 8:e71493. doi: 10.1371/journal.pone.0071493

Bourin, P., Ledain, A. F., Beau, J., Mille, D., and Levi, F. (2002). In-vitro circadian rhythm of murine bone marrow progenitor production. Chronobiol. Int. 19, 57-67. doi: 10.1081/CBI-120002677

Bray, M. S., and Young, M. E. (2007). Circadian rhythms in the development of obesity: potential role for the circadian clock within the adipocyte. Obes. Rev. 8 , 169-181. doi: 10.1111/j.1467-789X.2006.00277.x

Byrne, J. A., Grieve, D. J., Cave, A. C., and Shah, A. M. (2003). Oxidative stress and heart failure. Arch. Mal. Coeur Vaiss. 96, 214-221.

Chandrasekar, B., Colston, J. T., De La Rosa, S. D., Rao, P. P., and Freeman, G. L. (2003). TNF-alpha and H2O2 induce IL-18 and IL-18R beta expression in cardiomyocytes via NF-kappa B activation. Biochem. Biophys. Res. Commun. 303, 1152-1158. doi: 10.1016/S0006-291X(03)00496-0

Chintalgattu, V., and Katwa, L. C. (2004). Role of protein kinase Cdelta in endothelin-induced type I collagen expression in cardiac myofibroblasts isolated 
from the site of myocardial infarction. J. Pharmacol. Exp. Ther. 311, 691-699. doi: 10.1124/jpet.104.070151

Chu, L. W., Zhu, Y., Yu, K., Zheng, T., Yu, H., Zhang, Y., et al. (2008). Variants in circadian genes and prostate cancer risk: a population-based study in China. Prostate Cancer Prostatic Dis. 11, 342-348. doi: 10.1038/sj.pcan.45 01024

Clairambault, J. (2008). A step toward optimization of cancer therapeutics. Physiologically based modeling of circadian control on cell proliferation. IEEE Eng. Med. Biol. Mag. 27, 20-24. doi: 10.1109/MEMB.2007.907363

Cleutjens, J. P., Kandala, J. C., Guarda, E., Guntaka, R. V., and Weber, K. T. (1995). Regulation of collagen degradation in the rat myocardium after infarction. J. Mol. Cell. Cardiol. 27, 1281-1292. doi: 10.1016/S0022-2828(05)82390-9

Cohen, M. V., Yang, X. M., and Downey, J. M. (2006). Nitric oxide is a preconditioning mimetic and cardioprotectant and is the basis of many available infarct-sparing strategies. Cardiovasc. Res. 70, 231-239. doi: 10.1016/j.cardiores.2005.10.021

Cohen, R. A. (1995). The role of nitric oxide and other endothelium-derived vasoactive substances in vascular disease. Prog. Cardiovasc. Dis. 38, 105-128. doi: 10.1016/S0033-0620(05)80002-7

Corwin, J. V., and Vargo, J. M. (1993). Light deprivation produces accelerated behavioral recovery of function from neglect produced by unilateral medial agranular prefrontal cortex lesions in rats. Behav. Brain Res. 56, 187-196. doi: 10.1016/0166-4328(93)90038-R

Costa, A. D., and Garlid, K. D. (2008). Intramitochondrial signaling: interactions among mitoKATP, PKCepsilon, ROS, and MPT. Am. J. Physiol. Heart Circ. Physiol. 295, H874-H882. doi: 10.1152/ajpheart.01189.2007

Costa, A. D., Garlid, K. D., West, I. C., Lincoln, T. M., Downey, J. M., Cohen, M. V., et al. (2005). Protein kinase G transmits the cardioprotective signal from cytosol to mitochondria. Circ. Res. 97, 329-336. doi: 10.1161/01.RES.0000178451.08719.5b

Cozzi, E., Hazarika, S., Stallings, H. W. 3rd., Cascio, W. E., Devlin, R. B., Lust, R. M., et al. (2006). Ultrafine particulate matter exposure augments ischemiareperfusion injury in mice. Am. J. Physiol. Heart Circ. Physiol. 291, H894-H903. doi: 10.1152/ajpheart.01362.2005

Crisostomo, P. R., Wairiuko, G. M., Wang, M., Tsai, B. M., Morrell, E. D., and Meldrum, D. R. (2006). Preconditioning versus postconditioning: mechanisms and therapeutic potentials. J. Am. Coll. Surg. 202, 797-812. doi: 10.1016/j.jamcollsurg.2005.12.002

Curtis, A. M., Bellet, M. M., Sassone-Corsi, P., and O’Neill, L. A. (2014). Circadian clock proteins and immunity. Immunity 40, 178-186. doi: 10.1016/j.immuni.2014.02.002

Dardente, H., and Cermakian, N. (2005). [How many pieces to build a circadian clock?]. Med. Sci. (Paris) 21, 66-72. doi: 10.1051/medsci/200521166

Das, S., Wong, R., Rajapakse, N., Murphy, E., and Steenbergen, C. (2008). Glycogen synthase kinase 3 inhibition slows mitochondrial adenine nucleotide transport and regulates voltage-dependent anion channel phosphorylation. Circ. Res. 103, 983-991. doi: 10.1161/CIRCRESAHA.108.178970

Date, T., Mochizuki, S., Belanger, A. J., Yamakawa, M., Luo, Z., Vincent, K. A., et al. (2005). Expression of constitutively stable hybrid hypoxiainducible factor-1alpha protects cultured rat cardiomyocytes against simulated ischemia-reperfusion injury. Am. J. Physiol. Cell Physiol. 288, C314-C320. doi: 10.1152/ajpcell.00374.2004

Davidson, A. J., London, B., Block, G. D., and Menaker, M. (2005). Cardiovascular tissues contain independent circadian clocks. Clin. Exp. Hypertens. 27, 307-311. doi: 10.1081/CEH-48933

De Luca, G., Suryapranata, H., Ottervanger, J. P., Van't Hof, A. W., Hoorntje, J. C., Gosselink, A. T., et al. (2005). Circadian variation in myocardial perfusion and mortality in patients with ST-segment elevation myocardial infarction treated by primary angioplasty. Am. Heart J. 150, 1185-1189. doi: 10.1016/j.ahj.2005.01.057

Decoursey, P. J., Walker, J. K., and Smith, S. A. (2000). A circadian pacemaker in free-living chipmunks: essential for survival? J. Comp. Physiol. A 186, 169-180. doi: $10.1007 /$ s003590050017

Di Lisa, F., Canton, M., Menabo, R., Kaludercic, N., and Bernardi, P. (2007). Mitochondria and cardioprotection. Heart Fail. Rev. 12, 249-260. doi: 10.1007/s10741-007-9028-Z

Di Lisa, F., Menabo, R., Canton, M., and Petronilli, V. (1998). The role of mitochondria in the salvage and the injury of the ischemic myocardium. Biochim. Biophys. Acta 1366, 69-78. doi: 10.1016/S0005-2728(98)00121-2
Ding, J. M., Chen, D., Weber, E. T., Faiman, L. E., Rea, M. A., and Gillette, M. U. (1994). Resetting the biological clock: mediation of nocturnal circadian shifts by glutamate and NO. Science 266, 1713-1717. doi: 10.1126/science.7527589

Dominguez-Rodriguez, A., Abreu-Gonzalez, P., Garcia-Gonzalez, M., and Reiter, R. J. (2006a). Prognostic value of nocturnal melatonin levels as a novel marker in patients with ST-segment elevation myocardial infarction. Am. J. Cardiol. 97, 1162-1164. doi: 10.1016/j.amjcard.2005.11.033

Dominguez-Rodriguez, A., Garcia-Gonzalez, M., Abreu-Gonzalez, P., Ferrer, J., and Kaski, J. C. (2006b). Relation of nocturnal melatonin levels to C-reactive protein concentration in patients with ST-segment elevation myocardial infarction. Am. J. Cardiol. 97, 10-12. doi: 10.1016/j.amjcard.2005.07.120

Durgan, D. J., Hotze, M. A., Tomlin, T. M., Egbejimi, O., Graveleau, C., Abel, E. D., et al. (2005). The intrinsic circadian clock within the cardiomyocyte. Am. J. Physiol. Heart Circ. Physiol. 289, H1530-H1541. doi: 10.1152/ajpheart.00406.2005

Durgan, D. J., and Young, M. E. (2010). The cardiomyocyte circadian clock: emerging roles in health and disease. Circ. Res. 106, 647-658. doi: 10.1161/CIRCRESAHA.109.209957

Dvornyk, V., Vinogradova, O., and Nevo, E. (2003). Origin and evolution of circadian clock genes in prokaryotes. Proc. Natl. Acad. Sci. U.S.A. 100, 2495-2500. doi: 10.1073/pnas.0130099100

Eckle, T., Hartmann, K., Bonney, S., Reithel, S., Mittelbronn, M., Walker, L. A., et al. (2012). Adora2b-elicited Per2 stabilization promotes a HIF-dependent metabolic switch crucial for myocardial adaptation to ischemia. Nat. Med. 18, 774-782. doi: $10.1038 / \mathrm{nm} .2728$

Eltzschig, H. K., Bonney, S. K., and Eckle, T. (2013). Attenuating myocardial ischemia by targeting A2B adenosine receptors. Trends Mol. Med. 19, 345-354. doi: 10.1016/j.molmed.2013.02.005

Frangogiannis, N. G. (2006). The mechanistic basis of infarct healing. Antioxid. Redox Signal. 8, 1907-1939. doi: 10.1089/ars.2006.8.1907

Frangogiannis, N. G., and Entman, M. L. (2005). Chemokines in myocardial ischemia. Trends Cardiovasc. Med. 15, 163-169. doi: 10.1016/j.tcm.2005.06.005

Frangogiannis, N. G., Smith, C. W., and Entman, M. L. (2002). The inflammatory response in myocardial infarction. Cardiovasc. Res. 53, 31-47. doi: 10.1016/S0008-6363(01)00434-5

Frangogiannis, N. G., Youker, K. A., and Entman, M. L. (1996). The role of the neutrophil in myocardial ischemia and reperfusion. EXS 76, 263-284.

Fujino, Y., Iso, H., Tamakoshi, A., Inaba, Y., Koizumi, A., Kubo, T., et al. (2006). A prospective cohort study of shift work and risk of ischemic heart disease in Japanese male workers. Am. J. Epidemiol. 164, 128-135. doi: 10.1093/aje/ kwj185

Fukuhara, C., and Tosini, G. (2003). Peripheral circadian oscillators and their rhythmic regulation. Front. Biosci. 8, d642-d651. doi: 10.2741/1042

Garlid, K. D., Costa, A. D., Quinlan, C. L., Pierre, S. V., and Dos Santos, P. (2009). Cardioprotective signaling to mitochondria. J. Mol. Cell. Cardiol. 46, 858-866. doi: 10.1016/j.yjmcc.2008.11.019

Genade, S., Ytrehus, K., and Lochner, A. (2006). Melatonin prevents cardioprotection induced by a multi-cycle ischaemic preconditioning protocol in the isolated perfused rat heart. Cardiovasc. J. S. Afr. 17, 239-244.

Ghorbel, M. T., Coulson, J. M., and Murphy, D. (2003). Cross-talk between hypoxic and circadian pathways: cooperative roles for hypoxia-inducible factor lalpha and CLOCK in transcriptional activation of the vasopressin gene. Mol. Cell. Neurosci. 22, 396-404. doi: 10.1016/S1044-7431(02)00019-2

Giordano, F. J. (2005). Oxygen, oxidative stress, hypoxia, and heart failure. J. Clin. Invest. 115, 500-508. doi: 10.1172/JCI200524408

Glossop, N. R., Lyons, L. C., and Hardin, P. E. (1999). Interlocked feedback loops within the Drosophila circadian oscillator. Science 286, 766-768. doi: 10.1126/science. 286.5440 .766

Granados-Fuentes, D., and Herzog, E. D. (2013). The clock shop: coupled circadian oscillators. Exp. Neurol. 243, 21-27. doi: 10.1016/j.expneurol.2012.10.011

Granda, T. G., Liu, X. H., Smaaland, R., Cermakian, N., Filipski, E., SassoneCorsi, P., et al. (2005). Circadian regulation of cell cycle and apoptosis proteins in mouse bone marrow and tumor. FASEB J. 19, 304-306. doi: 10.1096/fj.042665fje

Green, C. B., Takahashi, J. S., and Bass, J. (2008). The meter of metabolism. Cell 134, 728-742. doi: 10.1016/j.cell.2008.08.022

Gross, E. R., Hsu, A. K., and Gross, G. J. (2004). Opioid-induced cardioprotection occurs via glycogen synthase kinase beta inhibition during reperfusion in intact rat hearts. Circ. Res. 94, 960-966. doi: 10.1161/01.RES.0000122392.33172.09 
Gross, E. R., Hsu, A. K., and Gross, G. J. (2006). The JAK/STAT pathway is essential for opioid-induced cardioprotection: JAK2 as a mediator of STAT3, Akt, and GSK-3 beta. Am. J. Physiol. Heart Circ. Physiol. 291, H827-H834. doi: 10.1152/ajpheart.00003.2006

Gross, E. R., Hsu, A. K., and Gross, G. J. (2007). GSK3beta inhibition and K(ATP) channel opening mediate acute opioid-induced cardioprotection at reperfusion. Basic Res. Cardiol. 102, 341-349. doi: 10.1007/s00395-007-0651-6

Guillaumond, F., Dardente, H., Giguere, V., and Cermakian, N. (2005). Differential control of Bmall circadian transcription by REV-ERB and ROR nuclear receptors. J. Biol. Rhythms 20, 391-403. doi: 10.1177/0748730405277232

Guo, H., Brewer, J. M., Champhekar, A., Harris, R. B., and Bittman, E. L. (2005). Differential control of peripheral circadian rhythms by suprachiasmaticdependent neural signals. Proc. Natl. Acad. Sci. U.S.A. 102, 3111-3116. doi: 10.1073/pnas.0409734102

Gupta, A., and Shetty, H. (2005). Circadian variation in stroke-a prospective hospital-based study. Int. J. Clin. Pract. 59, 1272-1275. doi: 10.1111/j.13685031.2005.00678.x

Hamacher-Brady, A., Brady, N. R., and Gottlieb, R. A. (2006). The interplay between pro-death and pro-survival signaling pathways in myocardial ischemia/reperfusion injury: apoptosis meets autophagy. Cardiovasc. Drugs Ther. 20, 445-462. doi: 10.1007/s10557-006-0583-7

Hardeland, R., Coto-Montes, A., and Poeggeler, B. (2003). Circadian rhythms, oxidative stress, and antioxidative defense mechanisms. Chronobiol. Int. 20, 921-962. doi: 10.1081/CBI-120025245

Hardin, P. E. (2006). Essential and expendable features of the circadian timekeeping mechanism. Curr. Opin. Neurobiol. 16, 686-692. doi: 10.1016/j.conb.2006.09.001

Hardin, P. E., and Glossop, N. R. (1999). Perspectives: neurobiology. The CRYs fo flies and mice. Science 286, 2460-2461. doi: 10.1126/science.286.5449.2460

Hardin, P. E., and Panda, S. (2013). Circadian timekeeping and output mechanisms in animals. Curr. Opin. Neurobiol. 23, 724-731. doi: 10.1016/j.conb.2013.02.018

Harmer, S. L., Panda, S., and Kay, S. A. (2001). Molecular bases of circadian rhythms. Annu. Rev. Cell Dev. Biol. 17, 215-253. doi: 10.1146/annurev.cellbio.17.1.215

Hausenloy, D. J., Tsang, A., and Yellon, D. M. (2005). The reperfusion injury salvage kinase pathway: a common target for both ischemic preconditioning and postconditioning. Trends Cardiovasc. Med. 15, 69-75. doi: 10.1016/j.tcm.2005.03.001

Hazarika, S., Van Scott, M. R., and Lust, R. M. (2004). Myocardial ischemiareperfusion injury is enhanced in a model of systemic allergy and asthma. Am. J. Physiol. Heart Circ. Physiol. 286, H1720-H1725. doi: 10.1152/ajpheart.01064.2003

Herzog, E. D., and Schwartz, W. J. (2002). A neural clockwork for encoding circadian time. J. Appl. Physiol. 92, 401-408. doi: 10.1152/japplphysiol.00836.2001

Holmes, J. W., Borg, T. K., and Covell, J. W. (2005). Structure and mechanics of healing myocardial infarcts. Annu. Rev. Biomed. Eng. 7, 223-253. doi: 10.1146/annurev.bioeng.7.060804.100453

Honma, S., Ikeda, M., Abe, H., Tanahashi, Y., Namihira, M., Honma, K., et al. (1998). Circadian oscillation of BMAL1, a partner of a mammalian clock gene Clock, in rat suprachiasmatic nucleus. Biochem. Biophys. Res. Commun. 250, 83-87. doi: 10.1006/bbrc.1998.9275

Izzedine, H., Launay-Vacher, V., and Deray, G. (2006). Abnormal blood pressure circadian rhythm: a target organ damage? Int. J. Cardiol. 107, 343-349. doi: 10.1016/j.ijcard.2005.03.046

Jeyaraj, D., Haldar, S. M., Wan, X., McCauley, M. D., Ripperger, J. A., Hu, K., et al. (2012). Circadian rhythms govern cardiac repolarization and arrhythmogenesis. Nature 483, 96-99. doi: 10.1038/nature10852

Jilma, B., Hergovich, N., Stohlawetz, P., Eichler, H. G., Bauer, P., and Wagner, O. F. (1999). Circadian variation of granulocyte colony stimulating factor levels in man. Br. J. Haematol. 106, 368-370. doi: 10.1046/j.1365-2141.1999. 01543.x

Jones, S. P., and Bolli, R. (2006). The ubiquitous role of nitric oxide in cardioprotection. J. Mol. Cell. Cardiol. 40, 16-23. doi: 10.1016/j.yjmcc.2005.09.011

Jones, S. P., Girod, W. G., Granger, D. N., Palazzo, A. J., and Lefer, D. J. (1999). Reperfusion injury is not affected by blockade of P-selectin in the diabetic mouse heart. Am. J. Physiol. 277, H763-H769.

Jordan, J. E., Zhao, Z. Q., and Vinten-Johansen, J. (1999). The role of neutrophils in myocardial ischemia-reperfusion injury. Cardiovasc. Res. 43, 860-878. doi: 10.1016/S0008-6363(99)00187-X
Kaminski, K. A., Bonda, T. A., Korecki, J., and Musial, W. J. (2002). Oxidative stress and neutrophil activation-the two keystones of ischemia/reperfusion injury. Int. J. Cardiol. 86, 41-59. doi: 10.1016/S0167-5273(02)00189-4

Kanth, R., Ittaman, S., and Rezkalla, S. (2013). Circadian patterns of ST elevation myocardial infarction in the new millennium. Clin. Med. Res. 11, 66-72. doi: $10.3121 / \mathrm{cmr} .2013 .1120$

Kawachi, I., Colditz, G. A., Stampfer, M. J., Willett, W. C., Manson, J. E., Speizer, F. E., et al. (1995). Prospective study of shift work and risk of coronary heart disease in women. Circulation 92, 3178-3182. doi: 10.1161/01.CIR.92.11.3178

Kawano, H., and Ogawa, H. (2005). Endothelial function and coronary spastic angina. Intern. Med. 44, 91-99. doi: 10.2169/internalmedicine.44.91

Knutsson, A., Akerstedt, T., Jonsson, B. G., and Orth-Gomer, K. (1986). Increased risk of ischaemic heart disease in shift workers. Lancet 2, 89-92. doi: 10.1016/S0140-6736(86)91619-3

Koyanagi, S., Kuramoto, Y., Nakagawa, H., Aramaki, H., Ohdo, S., Soeda, S., et al. (2003). A molecular mechanism regulating circadian expression of vascular endothelial growth factor in tumor cells. Cancer Res. 63, 7277-7283.

Krieg, T., Cohen, M. V., and Downey, J. M. (2003). Mitochondria and their role in preconditioning's trigger phase. Basic Res. Cardiol. 98, 228-234. doi: 10.1007/s00395-003-0422-y

Kumar, D., and Jugdutt, B. I. (2003). Apoptosis and oxidants in the heart. J. Lab. Clin. Med. 142, 288-297. doi: 10.1016/S0022-2143(03)00148-3

Kume, K., Zylka, M. J., Sriram, S., Shearman, L. P., Weaver, D. R., Jin, X., et al. (1999). mCRY1 and mCRY2 are essential components of the negative limb of the circadian clock feedback loop. Cell 98, 193-205. doi: 10.1016/S00928674(00)81014-4

Kyriacou, C. P., and Hall, J. C. (1980). Circadian rhythm mutations in Drosophila melanogaster affect short-term fluctuations in the male's courtship song. Proc. Natl. Acad. Sci. U.S.A. 77, 6729-6733. doi: 10.1073/pnas.77.11.6729

Lapenna, D., De Gioia, S., Mezzetti, A., Porreca, E., Ciofani, G., Marzio, L., et al. (1992). Circadian variations in antioxidant defences and lipid peroxidation in the rat heart. Free Radic. Res. Commun. 17, 187-194. doi: $10.3109 / 10715769209068165$

Lee, C., Etchegaray, J. P., Cagampang, F. R., Loudon, A. S., and Reppert, S. M. (2001). Posttranslational mechanisms regulate the mammalian circadian clock. Cell 107, 855-867. doi: 10.1016/S0092-8674(01)00610-9

Lee, K. W., Blann, A. D., and Lip, G. Y. (2005). High pulse pressure and nondipping circadian blood pressure in patients with coronary artery disease: relationship to thrombogenesis and endothelial damage/dysfunction. Am. J. Hypertens. 18, 104-115. doi: 10.1016/j.amjhyper.2004.09.003

Lemmer, B. (2006). The importance of circadian rhythms on drug response in hypertension and coronary heart disease-from mice and man. Pharmacol. Ther 111, 629-651. doi: 10.1016/j.pharmthera.2005.11.008

Lipkova, J., Splichal, Z., Bienertova-Vasku, J. A., Jurajda, M., Parenica, J., Vasku, A., et al. (2014). Period3 VNTR polymorphism influences the time-of-day pain onset of acute myocardial infarction with ST elevation. Chronobiol. Int. 31, 878-890. doi: 10.3109/07420528.2014.921790

Liu, J., Mankani, G., Shi, X., Meyer, M., Cunningham-Runddles, S., Ma, X., et al. (2006). The circadian clock Period 2 gene regulates gamma interferon production of NK cells in host response to lipopolysaccharide-induced endotoxic shock. Infect. Immun. 74, 4750-4756. doi: 10.1128/IAI.00287-06

Lopez, F., Lee, K. W., Marin, F., Roldan, V., Sogorb, F., Caturla, J., et al. (2005). Are there ethnic differences in the circadian variation in onset of acute myocardial infarction? A comparison of 3 ethnic groups in Birmingham, UK and Alicante, Spain. Int. J. Cardiol. 100, 151-154. doi: 10.1016/j.ijcard.2004.12.002

Lyle, A. N., and Griendling, K. K. (2006). Modulation of vascular smooth muscle signaling by reactive oxygen species. Physiology (Bethesda) 21, 269-280. doi: 10.1152/physiol.00004.2006

Marin-Garcia, J., and Goldenthal, M. J. (2004). Mitochondria play a critical role in cardioprotection. J. Card. Fail. 10, 55-66. doi: 10.1016/S1071-9164(03) 00129-5

Martino, T. A., Oudit, G. Y., Herzenberg, A. M., Tata, N., Koletar, M. M., Kabir, G. M., et al. (2008). Circadian rhythm disorganization produces profound cardiovascular and renal disease in hamsters. Am. J. Physiol. Regul. Integr. Comp. Physiol. 294, R1675-R1683. doi: 10.1152/ajpregu.00829.2007

Martino, T. A., Tata, N., Belsham, D. D., Chalmers, J., Straume, M., Lee, P., et al. (2007). Disturbed diurnal rhythm alters gene expression and exacerbates cardiovascular disease with rescue by resynchronization. Hypertension 49, 1104-1113. doi: 10.1161/HYPERTENSIONAHA.106.083568 
Mattson, M. P., and Kroemer, G. (2003). Mitochondria in cell death: novel targets for neuroprotection and cardioprotection. Trends Mol. Med. 9, 196-205. doi: 10.1016/S1471-4914(03)00046-7

Maulik, N. (2006). Reactive oxygen species drives myocardial angiogenesis? Antioxid. Redox Signal. 8, 2161-2168. doi: 10.1089/ars.2006.8.2161

Maury, E., Ramsey, K. M., and Bass, J. (2010). Circadian rhythms and metabolic syndrome: from experimental genetics to human disease. Circ. Res. 106, 447-462. doi: 10.1161/CIRCRESAHA.109.208355

Maywood, E. S., Fraenkel, E., McAllister, C. J., Wood, N., Reddy, A. B., Hastings, M. H., et al. (2010). Disruption of peripheral circadian timekeeping in a mouse model of Huntington's disease and its restoration by temporally scheduled feeding. J. Neurosci. 30, 10199-10204. doi: 10.1523/JNEUROSCI.1694-10.2010

McNamara, P., Seo, S. P., Rudic, R. D., Sehgal, A., Chakravarti, D., and Fitzgerald, G. A. (2001). Regulation of CLOCK and MOP4 by nuclear hormone receptors in the vasculature: a humoral mechanism to reset a peripheral clock. Cell 105, 877-889. doi: 10.1016/S0092-8674(01)00401-9

Mendez-Ferrer, S., Lucas, D., Battista, M., and Frenette, P. S. (2008). Haematopoietic stem cell release is regulated by circadian oscillations. Nature 452, 442-447. doi: 10.1038/nature06685

Merrow, M., Spoelstra, K., and Roenneberg, T. (2005). The circadian cycle: daily rhythms from behaviour to genes. EMBO Rep. 6, 930-935. doi: 10.1038/sj.embor.7400541

Morgan, T. O. (2002). Is non-dipping status a predictor of cardiac morbidity? J. Hypertens. 20, 1469-1471. doi: 10.1097/00004872-200208000-00003

Mormont, M. C., Waterhouse, J., Bleuzen, P., Giacchetti, S., Jami, A., Bogdan, A., et al. (2000). Marked 24-h rest/activity rhythms are associated with better quality of life, better response, and longer survival in patients with metastatic colorectal cancer and good performance status. Clin. Cancer Res. 6, 3038-3045.

Mosendane, T., and Raal, F. J. (2008). Shift work and its effects on the cardiovascular system. Cardiovasc. J. Afr. 19, 210-215.

Mozaffari, M. S., and Schaffer, S. W. (2008). Effect of pressure overload on cardioprotection of mitochondrial KATP channels and GSK-3beta: interaction with the MPT pore. Am. J. Hypertens. 21, 570-575. doi: 10.1038/ajh.2008.25

Mukamal, K. J., Muller, J. E., Maclure, M., Sherwood, J. B., and Mittleman, M. A. (2000). Increased risk of congestive heart failure among infarctions with nighttime onset. Am. Heart J. 140, 438-442. doi: $10.1067 / \mathrm{mhj} .2000 .108830$

Muller, J. E. (1999a). Circadian variation and triggering of acute coronary events. Am. Heart J. 137, S1-S8. doi: 10.1016/S0002-8703(99)70390-X

Muller, J. E. (1999b). Circadian variation in cardiovascular events. Am. J. Hypertens. $12,35 \mathrm{~S}-42 \mathrm{~S}$.

Murphy, E. (2004). Inhibit GSK-3beta or there's heartbreak dead ahead. J. Clin. Invest. 113, 1526-1528. doi: 10.1172/JCI21986

Murphy, E., and Steenbergen, C. (2005). Inhibition of GSK-3beta as a target for cardioprotection: the importance of timing, location, duration and degree of inhibition. Expert Opin. Ther. Targets 9, 447-456. doi: 10.1517/14728222.9.3.447

Murphy, E., and Steenbergen, C. (2007). Preconditioning: the mitochondrial connection. Annu. Rev. Physiol. 69, 51-67. doi: 10.1146/annurev.physiol.69.031905.163645

Nagoshi, E., Brown, S. A., Dibner, C., Kornmann, B., and Schibler, U. (2005). Circadian gene expression in cultured cells. Meth. Enzymol. 393, 543-557. doi: 10.1016/S0076-6879(05)93028-0

Nagoshi, E., Saini, C., Bauer, C., Laroche, T., Naef, F., and Schibler, U. (2004). Circadian gene expression in individual fibroblasts: cell-autonomous and selfsustained oscillators pass time to daughter cells. Cell 119, 693-705. doi: 10.1016/j.cell.2004.11.015

Naito, Y., Tsujino, T., Kawasaki, D., Okumura, T., Morimoto, S., Masai, M., et al. (2003). Circadian gene expression of clock genes and plasminogen activator inhibitor- 1 in heart and aorta of spontaneously hypertensive and Wistar-Kyoto rats. J. Hypertens. 21, 1107-1115. doi: 10.1097/00004872-200306000-00010

Nedeltcheva, A. V., and Scheer, F. A. (2014). Metabolic effects of sleep disruption, links to obesity and diabetes. Curr. Opin. Endocrinol. Diabetes Obes. 21, 293-298. doi: 10.1097/MED.0000000000000082

Nian, M., Lee, P., Khaper, N., and Liu, P. (2004). Inflammatory cytokines and postmyocardial infarction remodeling. Circ. Res. 94, 1543-1553. doi 10.1161/01.RES.0000130526.20854.fa

Nonaka, H., Emoto, N., Ikeda, K., Fukuya, H., Rohman, M. S., Raharjo, S. B., et al. (2001). Angiotensin II induces circadian gene expression of clock genes in cultured vascular smooth muscle cells. Circulation 104, 1746-1748. doi: 10.1161/hc4001.098048
Oldenburg, O., Cohen, M. V., Yellon, D. M., and Downey, J. M. (2002). Mitochondrial K(ATP) channels: role in cardioprotection. Cardiovasc. Res. 55, 429-437. doi: 10.1016/S0008-6363(02)00439-X

Omar, M. A., Wang, L., and Clanachan, A. S. (2010). Cardioprotection by GSK3 Inhibition: role of enhanced glycogen synthesis and attenuation of calcium overload. Cardiovasc. Res. 86, 478-486. doi: 10.1093/cvr/cvp421

Opie, L. H., Commerford, P. J., Gersh, B. J., and Pfeffer, M. A. (2006). Controversies in ventricular remodelling. Lancet 367, 356-367. doi: 10.1016/S01406736(06)68074-4

Petrosillo, G., Colantuono, G., Moro, N., Ruggiero, F. M., Tiravanti, E., Di Venosa, N., et al. (2009). Melatonin protects against heart ischemia-reperfusion injury by inhibiting mitochondrial permeability transition pore opening. Am. J. Physiol. Heart Circ. Physiol. 297, H1487-H1493. doi: 10.1152/ajpheart.00163.2009

Pfeffer, M. A., and Braunwald, E. (1990). Ventricular remodeling after myocardial infarction. Experimental observations and clinical implications. Circulation 81, 1161-1172. doi: 10.1161/01.CIR.81.4.1161

Prasai, M. J., George, J. T., and Scott, E. M. (2008). Molecular clocks, type 2 diabetes and cardiovascular disease. Diab. Vasc. Dis. Res. 5, 89-95. doi: 10.3132/dvdr.2008.015

Reddy, A. B., and Maywood, E. S. (2007). Circadian rhythms: per2bations in the liver clock. Curr. Biol. 17, R292-R294. doi: 10.1016/j.cub.2007.02.031

Reddy, A. B., and Rey, G. (2014). Metabolic and nontranscriptional circadian clocks: eukaryotes. Annu. Rev. Biochem. 83, 165-189. doi: 10.1146/annurevbiochem-060713-035623

Reick, M., Garcia, J. A., Dudley, C., and McKnight, S. L. (2001). NPAS2: an ana$\log$ of clock operative in the mammalian forebrain. Science 293, 506-509. doi: 10.1126/science. 1060699

Reimer, K. A., and Jennings, R. B. (1979). The "wavefront phenomenon" of myocardial ischemic cell death. II. Transmural progression of necrosis within the framework of ischemic bed size (myocardium at risk) and collateral flow. Lab. Invest. 40, 633-644.

Reppert, S. M., and Weaver, D. R. (2002). Coordination of circadian timing in mammals. Nature 418, 935-941. doi: 10.1038/nature00965

Robinson, I., and Reddy, A. B. (2014). Molecular mechanisms of the circadian clockwork in mammals. FEBS Lett. 588, 2477-2483. doi: 10.1016/j.febslet.2014.06.005

Rossi, F. (1986). The O2- -forming NADPH oxidase of the phagocytes: nature, mechanisms of activation and function. Biochim. Biophys. Acta 853, 65-89. doi: 10.1016/0304-4173(86)90005-4

Rotrosen, D. (1992). The Respiratory Burst Oxidase. New York, NY: Raven.

Ruger, M., and Scheer, F. A. (2009). Effects of circadian disruption on the cardiometabolic system. Rev. Endocr. Metab. Disord. 10, 245-260. doi: $10.1007 / \mathrm{s} 11154-009-9122-8$

Sambandam, N., Morabito, D., Wagg, C., Finck, B. N., Kelly, D. P., and Lopaschuk, G. D. (2006). Chronic activation of PPARalpha is detrimental to cardiac recovery after ischemia. Am. J. Physiol. Heart Circ. Physiol. 290, H87-H95. doi: 10.1152/ajpheart.00285.2005

Sancar, A. (2000). Cryptochrome: the second photoactive pigment in the eye and its role in circadian photoreception. Annu. Rev. Biochem. 69, 31-67. doi: 10.1146/annurev.biochem.69.1.31

Sangoram, A. M., Saez, L., Antoch, M. P., Gekakis, N., Staknis, D., Whiteley, A., et al. (1998). Mammalian circadian autoregulatory loop: a timeless ortholog and mPer1 interact and negatively regulate CLOCK-BMAL1-induced transcription. Neuron 21, 1101-1113. doi: 10.1016/S0896-6273(00)80627-3

Savopoulos, C., Ziakas, A., Hatzitolios, A., Delivoria, C., Kounanis, A., Mylonas, S., et al. (2006). Circadian rhythm in sudden cardiac death: a retrospective study of 2,665 cases. Angiology 57, 197-204. doi: 10.1177/000331970605700210

Scadden, D. T. (2008). Circadian rhythms: stem cells traffic in time. Nature 452, 416-417. doi: 10.1038/452416a

Schwertz, H., Carter, J. M., Abdudureheman, M., Russ, M., Buerke, U., Schlitt, A., et al. (2007). Myocardial ischemia/reperfusion causes VDAC phosphorylation which is reduced by cardioprotection with a p38 MAP kinase inhibitor. Proteomics 7, 4579-4588. doi: 10.1002/pmic.200700734

Seal, J. B., and Gewertz, B. L. (2005). Vascular dysfunction in ischemia-reperfusion injury. Ann. Vasc. Surg. 19, 572-584. doi: 10.1007/s10016-005-4616-7

Semenza, G. L. (2001). Hypoxia-inducible factor 1: oxygen homeostasis and disease pathophysiology. Trends Mol. Med. 7, 345-350. doi: 10.1016/S14714914(01)02090-1 
Sephton, S. E., Sapolsky, R. M., Kraemer, H. C., and Spiegel, D. (2000). Diurnal cortisol rhythm as a predictor of breast cancer survival. J. Natl. Cancer Inst. 92, 994-1000. doi: 10.1093/jnci/92.12.994

Shearman, L. P., Jin, X., Lee, C., Reppert, S. M., and Weaver, D. R. (2000). Targeted disruption of the mPer3 gene: subtle effects on circadian clock function. Mol. Cell. Biol. 20, 6269-6275. doi: 10.1128/MCB.20.17.6269-6275.2000

Squires, C. E., Escobar, G. P., Payne, J. F., Leonardi, R. A., Goshorn, D. K., Sheats, N. J., et al. (2005). Altered fibroblast function following myocardial infarction. J. Mol. Cell. Cardiol. 39, 699-707. doi: 10.1016/j.yjmcc.2005.07.008

Stanley, W. C. (2004). Myocardial energy metabolism during ischemia and the mechanisms of metabolic therapies. J. Cardiovasc. Pharmacol. Ther. 9(Suppl. 1), S31-S45. doi: 10.1177/107424840400900104

Sun, Y., Kiani, M. F., Postlethwaite, A. E., and Weber, K. T. (2002). Infarct scar as living tissue. Basic Res. Cardiol. 97, 343-347. doi: 10.1007/s00395-002-0365-8

Sun, Z. S., Albrecht, U., Zhuchenko, O., Bailey, J., Eichele, G., and Lee, C. C. (1997). RIGUI, a putative mammalian ortholog of the Drosophila period gene. Cell 90, 1003-1011. doi: 10.1016/S0092-8674(00)80366-9

Suzuki, K., Murtuza, B., Smolenski, R. T., Sammut, I. A., Suzuki, N., Kaneda, Y., et al. (2001). Overexpression of interleukin-1 receptor antagonist provides cardioprotection against ischemia-reperfusion injury associated with reduction in apoptosis. Circulation 104, I308-I313. doi: 10.1161/hc37t1.094871

Takayama, T., Wada, A., Tsutamoto, T., Ohnishi, M., Fujii, M., Isono, T., et al. (2004). Contribution of vascular NAD(P)H oxidase to endothelial dysfunction in heart failure and the therapeutic effects of HMG-CoA reductase inhibitor. Circ. J. 68, 1067-1075. doi: 10.1253/circj.68.1067

Taniyama, Y., and Griendling, K. K. (2003). Reactive oxygen species in the vasculature: molecular and cellular mechanisms. Hypertension 42, 1075-1081. doi: 10.1161/01.HYP.0000100443.09293.4F

Thresher, R. J., Vitaterna, M. H., Miyamoto, Y., Kazantsev, A., Hsu, D. S., Petit, C., et al. (1998). Role of mouse cryptochrome blue-light photoreceptor in circadian photoresponses. Science 282, 1490-1494. doi: 10.1126/science.282.53 93.1490

Tong, H., Imahashi, K., Steenbergen, C., and Murphy, E. (2002). Phosphorylation of glycogen synthase kinase-3beta during preconditioning through a phosphatidylinositol-3-kinase-dependent pathway is cardioprotective. Circ. Res. 90, 377-379. doi: 10.1161/01.RES.0000012567.95445.55

Tsimakouridze, E. V., Straume, M., Podobed, P. S., Chin, H., Lamarre, J., Johnson, R., et al. (2012). Chronomics of pressure overload-induced cardiac hypertrophy in mice reveals altered day/night gene expression and biomarkers of heart disease. Chronobiol. Int. 29, 810-821. doi: 10.3109/07420528.2012. 691145

Tsinkalovsky, O., Rosenlund, B., Laerum, O. D., and Eiken, H. G. (2005). Clock gene expression in purified mouse hematopoietic stem cells. Exp. Hematol. 33, 100-107. doi: 10.1016/j.exphem.2004.09.007

Tsinkalovsky, O., Smaaland, R., Rosenlund, B., Sothern, R. B., Hirt, A., Steine, S., et al. (2007). Circadian variations in clock gene expression of human bone marrow CD34+ cells. J. Biol. Rhythms 22, 140-150. doi: 10.1177/07487304062 99078

Tsuchiya, Y., Minami, I., Kadotani, H., and Nishida, E. (2005). Resetting of peripheral circadian clock by prostaglandin E2. EMBO Rep. 6, 256-261. doi: 10.1038/sj.embor.7400356

Tsujino, T., Naito, Y., Kawasaki, D., Okuda, S., Sakoda, T., Fujioka, Y., et al. (2005). Circadian expression of plasminogen activator inhibitor-1 in angiotensin II type 1a receptor knockout mice. Clin. Exp. Hypertens. 27, 159-168. doi: 10.1081/CEH-48744

Vanhoutte, D., Schellings, M., Pinto, Y., and Heymans, S. (2006). Relevance of matrix metalloproteinases and their inhibitors after myocardial infarction: a temporal and spatial window. Cardiovasc. Res. 69, 604-613. doi: 10.1016/j.cardiores.2005.10.002

Vargo, J. M., Grachek, R. A., and Rockswold, G. L. (1999). Light deprivation soon after frontal brain trauma accelerates recovery from attentional deficits and promotes functional normalization of basal ganglia. J. Trauma 47, 265-272. discussion: 273-264.

Vargo, J. M., Lai, H. V., and Marshall, J. F. (1998). Light deprivation accelerates recovery from frontal cortical neglect: relation to locomotion and striatal Fos expression. Behav. Neurosci. 112, 387-398. doi: 10.1037/0735-7044. 112.2.387

Vaughan, D. E. (2005). PAI-1 and atherothrombosis. J. Thromb. Haemost. 3, 1879-1883. doi: 10.1111/j.1538-7836.2005.01420.x
Virag, J. A., Anderson, E. J., Kent, S. D., Blanton, H. D., Johnson, T. L., Moukdar, F., et al. (2013). Cardioprotection via preserved mitochondrial structure and function in the mPer2-mutant mouse myocardium. Am. J. Physiol. Heart Circ. Physiol. 305, H477-H483. doi: 10.1152/ajpheart.009 14.2012

Virag, J. A., Dries, J. L., Easton, P. R., Friesland, A. M., Deantonio, J. H., Chintalgattu, V., et al. (2010). Attenuation of myocardial injury in mice with functional deletion of the circadian rhythm gene mPer2. Am. J. Physiol. Heart Circ. Physiol. 298, H1088-H1095. doi: 10.1152/ajpheart.012 80.2008

Virag, J. I., and Murry, C. E. (2003). Myofibroblast and endothelial cell proliferation during murine myocardial infarct repair. Am. J. Pathol. 163, 2433-2440. doi: 10.1016/S0002-9440(10)63598-5

Viswambharan, H., Carvas, J. M., Antic, V., Marecic, A., Jud, C., Zaugg, C. E., et al. (2007). Mutation of the circadian clock gene Per2 alters vascular endothelial function. Circulation 115, 2188-2195. doi: 10.1161/CIRCULATIONAHA.106.653303

Vukolic, A., Antic, V., Van Vliet, B. N., Yang, Z., Albrecht, U., and Montani, J. P. (2010). Role of mutation of the circadian clock gene Per2 in cardiovascular circadian rhythms. Am. J. Physiol. Regul. Integr. Comp. Physiol. 298, R627-R634. doi: 10.1152/ajpregu.00404.2009

Walters, J. F., Hampton, S. M., Deanfield, J. E., Donald, A. E., Skene, D. J., and Ferns, G. A. (2006). Circadian variation in endothelial function is attenuated in postmenopausal women. Maturitas 54, 294-303. doi: 10.1016/j.maturitas.2005.12.005

Welbourn, C. R., Goldman, G., Paterson, I. S., Valeri, C. R., Shepro, D., and Hechtman, H. B. (1991). Pathophysiology of ischaemia reperfusion injury: central role of the neutrophil. Br. J. Surg. 78, 651-655. doi: 10.1002/bjs.18007 80607

Willich, S. N., Kulig, M., and Muller-Nordhorn, J. (2004). European survey on circadian variation of angina pectoris (ESCVA) in treated patients. Herz 29, 665-672. doi: 10.1007/s00059-004-2536-x

Wong, R., Aponte, A. M., Steenbergen, C., and Murphy, E. (2010). Cardioprotection leads to novel changes in the mitochondrial proteome. Am. J. Physiol. Heart Circ. Physiol. 298, H75-H91. doi: 10.1152/ajpheart.00515.2009

Wu, L., and Reddy, A. B. (2014). Rethinking the clockwork: redox cycles and nontranscriptional control of circadian rhythms. Biochem. Soc. Trans. 42, 1-10. doi: 10.1042/BST20130169

Xu, Y., Toh, K. L., Jones, C. R., Shin, J. Y., Fu, Y. H., and Ptacek, L. J. (2007). Modeling of a human circadian mutation yields insights into clock regulation by PER2. Cell 128, 59-70. doi: 10.1016/j.cell.2006.11.043

Yagita, K., Yamaguchi, S., Tamanini, F., Van Der Horst, G. T., Hoeijmakers, J. H., Yasui, A., et al. (2000). Dimerization and nuclear entry of mPER proteins in mammalian cells. Genes Dev. 14, 1353-1363. doi: 10.1101/gad.14.11.1353

Yagita, K., Yamanaka, I., Emoto, N., Kawakami, K., and Shimada, S. (2010). Real-time monitoring of circadian clock oscillations in primary cultures of mammalian cells using Tol2 transposon-mediated gene transfer strategy. BMC Biotechnol. 10:3. doi: 10.1186/1472-6750-10-3

Yamakawa, M., Liu, L. X., Date, T., Belanger, A. J., Vincent, K. A., Akita, G. Y., et al. (2003). Hypoxia-inducible factor-1 mediates activation of cultured vascular endothelial cells by inducing multiple angiogenic factors. Circ. Res. 93, 664-673. doi: 10.1161/01.RES.0000093984.48643.D7

Yang, X., Wood, P. A., Oh, E. Y., Du-Quiton, J., Ansell, C. M., and Hrushesky, W. J. (2008). Down regulation of circadian clock gene Period 2 accelerates breast cancer growth by altering its daily growth rhythm. Breast Cancer Res. Treat. 117, 423-431. doi: 10.1007/s10549-008-0133-z

Young, M. E. (2006). The circadian clock within the heart: potential influence on myocardial gene expression, metabolism, and function. Am. J. Physiol. Heart Circ. Physiol. 290, H1-H16. doi: 10.1152/ajpheart.00582.2005

Young, M. E., Razeghi, P., Cedars, A. M., Guthrie, P. H., and Taegtmeyer, H. (2001a). Intrinsic diurnal variations in cardiac metabolism and contractile function. Circ. Res. 89, 1199-1208. doi: 10.1161/hh2401. 100741

Young, M. E., Razeghi, P., and Taegtmeyer, H. (2001b). Clock genes in the heart: characterization and attenuation with hypertrophy. Circ. Res. 88, 1142-1150. doi: 10.1161/hh1101.091190

Zhao, Z. Q., and Vinten-Johansen, J. (2006). Postconditioning: reduction of reperfusion-induced injury. Cardiovasc. Res. 70, 200-211. doi: 10.1016/j.cardiores.2006.01.024 
Zheng, B., Larkin, D. W., Albrecht, U., Sun, Z. S., Sage, M., Eichele, G., et al. (1999). The mPer2 gene encodes a functional component of the mammalian circadian clock. Nature 400, 169-173. doi: 10.1038/22659

Conflict of Interest Statement: The authors declare that the research was conducted in the absence of any commercial or financial relationships that could be construed as a potential conflict of interest.

Received: 27 August 2014; accepted: 12 October 2014; published online: 30 October 2014.
Citation: Virag JAI and Lust RM (2014) Circadian influences on myocardial infarction. Front. Physiol. 5:422. doi: 10.3389/fphys.2014.00422

This article was submitted to Integrative Physiology, a section of the journal Frontiers in Physiology.

Copyright (c) 2014 Virag and Lust. This is an open-access article distributed under the terms of the Creative Commons Attribution License (CC BY). The use, distribution or reproduction in other forums is permitted, provided the original author(s) or licensor are credited and that the original publication in this journal is cited, in accordance with accepted academic practice. No use, distribution or reproduction is permitted which does not comply with these terms. 